\title{
Sustainability transitions of contaminated sites: a global meta-analysis on economic effects of remediation behavior
}

\author{
Xiaonuo $\mathrm{Li}^{1}$, Shiyi $\mathrm{Yi}^{1}$, Andrew $\mathrm{Cundy}^{2}$, and Weiping Chen ${ }^{1}$ \\ ${ }^{1}$ Research Centre for Eco-Environmental Sciences Chinese Academy of Sciences \\ ${ }^{2}$ University of Southampton
}

February 4, 2022

\begin{abstract}
The worldwide diversity of contaminated sites, coupled with a scarcity of available land in urban spatial planning, has led to an increasing political significance for brownfield conservation and re-use to achieve land resource sustainability. In this study, economic or so-called rebound effects of land regeneration, are studied via a global meta-analysis on value fluctuation of surrounding property. To this end, a total of 91 observations from 28 HPM (Hedonic Pricing Model) studies were synthesized to conduct a meta-analysis following a conditional random-effects procedure. The empirical results indicate that, in line with expectations, the conservation and recycling of land resource indeed generate significant rebound in the implicit price of residential houses, especially for those located within 2 kilometers of contaminated sites. Before land remediation and reuse, dwellings closest in distance to contaminated sites experience the greatest value loss. On average, the depreciation in property values within the first $1 \mathrm{~km}$ distance from a contaminated site is about $8.18 \%$, significantly at the $1 \%$ level, while the corresponding adverse impact from 1 to $2 \mathrm{~km}$ distance is a $4.8 \%$ price premium significantly at the $5 \%$ level. The significance of the stigma or rebound effects depend on 12 attributes, in which, house age, location, FAR (Floor Area Ratio) and CBD (Central Business District) variables have the largest impact, of $-37.38 \% \sim 37.5 \%$. From a practical perspective, the findings of this meta-analysis: 1) help refine contributing parameters in HPM studies to evaluate environmental economics; and 2) provide meaningful decision-making support for cost-effective remediation and benefit maximization.
\end{abstract}

\section{Hosted file}

manuscript.R1.doc available at https://authorea.com/users/458819/articles/555284sustainability-transitions-of-contaminated-sites-a-global-meta-analysis-on-economiceffects-of-remediation-behavior 